\title{
Triple Crossover Study on Absorption and Excretion of Ampicillin, Pivampicillin, and Amoxycillin
}

\author{
L. VERBIST \\ Academisch Ziekenhuis, University of Leuven, Leuven, Belgium
}

Received for publication 1 July 1974

\begin{abstract}
The absorption and excretion of equivalent doses of ampicillin, pivampicillin, and amoxycillin were compared in 10 healthy volunteers after administration of these antibiotics in a randomized triple crossover fashion. As recommended, ampicillin and amoxycillin were administered on an empty stomach, whereas pivampicillin was given with breakfast. The mean half-life times were nearly identical for all three antibiotics: $60.9 \mathrm{~min}$ for ampicillin; $58.4 \mathrm{~min}$ for pivampicillin; and $62.2 \mathrm{~min}$ for amoxycillin. The absorption of the drugs was evaluated according to the following three criteria: the mean peak serum levels; the "area under the curve"; and the percentage of recovery in urine. By these criteria, pivampicillin was the best-absorbed drug, with absorption 3.0 to 3.6 times higher than that of ampicillin and 1.2 to 1.5 times higher than that of amoxycillin, whereas the absorption of amoxycillin was 2.1 to 2.9 times higher than that of ampicillin.
\end{abstract}

The discovery of ampicillin opened a new class of penicillins and broadened their spectrum of activity to a number of gram-negative bacilli. Unfortunately, the rather inefficient absorption after oral administration is a drawback, so that in serious infections the drug must be administered parenterally for maximal effectiveness. Over the last 10 years a number of attempts have been made to synthesize ampicillin analogues or ampicillin complexes that liberate ampicillin in vivo, in order to improve the oral absorption. Among the most promising of these new drugs are pivampicillin and amoxycillin.

Pivampicillin is a pivaloyloxymethyl ester of ampicillin that is hydrolyzed within a few minutes in vivo by esterases with liberation of ampicillin $(3,4)$. Amoxycillin is a $p$-hydroxy derivative of ampicillin that is very comparable to ampicillin in its antibacterial spectrum and in its activity in vitro $(12,14)$. Both drugs have been reported to give substantially higher serum levels than ampicillin after oral administration of comparable doses $(1,2,4-8,10,11$, 13). For better absorption, ampicillin and amoxycillin are administered on an empty stomach. According to the recommendation of the manufacturer and to avoid gastrointestinal disturbances, pivampicillin is administered with a meal.

This study compares in a randomized triple crossover fashion the absorption and excretion of equivalent doses of the three antibiotics, administered in the way normally recommended in clinical practice.

\section{MATERIALS AND METHODS}

Ten healthy adult volunteers, four males and six females between 22 and 43 years old, received alternately ampicillin-trihydraat (Bristol Laboratories), pivampicillin (Leo Pharmaceuticals), and amoxycillin (Bristol Laboratories) in a randomized crossover fashion, with an interval of 4 or more days between the different administrations. The single dose of ampicillin $(500 \mathrm{mg})$ or amoxycillin $(500 \mathrm{mg})$ was administered after an overnight fast and $30 \mathrm{~min}$ before breakfast, and the dose of pivampicillin $(700$ $\mathrm{mg}$ ), corresponding to $500 \mathrm{mg}$ of free ampicillin, was given with breakfast. Test persons were allowed to have breakfast, but it had to be identical in the three cases.

Serum levels were determined before and $1,1.5,2$, 4 , and $6 \mathrm{~h}$ after drug administration. The volunteers were asked to urinate just before the drugs were taken, and the urinary excretion of the active drugs was measured in the samples collected between 0 to 2,2 to 4,4 to 6 , and 6 to $9 \mathrm{~h}$ after drug administration.

The antibiotic concentrations were determined with an agar well method. The less susceptible Bacillus sphericus ATCC 10.208 was used as a test organism for the samples with high antibiotic concentrations, namely for the urine and serum levels between 1 and $4 \mathrm{~h}$, whereas the more susceptible Sarcinea lutea ATCC 9341 was used for low serum levels after $6 \mathrm{~h}$. One drop of the test organism grown in Trypticase soy broth (BBL) was inoculated into $50 \mathrm{ml}$ of fresh Trypticase soy broth and incubated at $37 \mathrm{C}$ for $18 \mathrm{~h}$. From this culture $1 \mathrm{ml}$ was added to $100 \mathrm{ml}$ of melted seed agar (BBL), and 14-ml amounts were 
poured into petri dishes (9-cm diameter) and allowed to harden on a perfectly horizontal table. The plates were cooled at $4 \mathrm{C}$ for at least $24 \mathrm{~h}$ before use, but they were stored no longer than 5 days. Six wells $(4 \mathrm{~mm}$ in diameter) at equal distances were cut out of the agar. The wells were filled with $0.02 \mathrm{ml}$ of undiluted serum specimens or with $0.02 \mathrm{ml}$ of urine specimens in appropriate dilutions. The urine samples were diluted with saline ( $1 / 100$ to $1 / 500$ and $1 / 1,000$ for the early samples and $1 / 10,1 / 50$, and $1 / 100$ for the late samples) so that the size of the inhibition zones fell within the range of the standard curves. After incubation at $37 \mathrm{C}$ for $18 \mathrm{~h}$, the inhibiton zones were measured with a nonius reader.

Appropriate standard dilutions of the drugs were prepared in pooled serum for the determination of the serum levels and in saline for the urine levels, with the use of standardized antibiotic batches of ampicillin and amoxycillin supplied by Bristol Laboratories Benelux. Out of eight twofold serial dilutions of from 10 to $0.15 \mu \mathrm{g} / \mathrm{ml}$ of each of the two antibiotics, the best fit of the exponential regression line $Y=a . e^{b X}$ was calculated. The regression line represents the relationship between the inhibition zone in millimeters $(X)$ and the concentration in micrograms per milliliter (Y). With B. sphericus as the test organism, the correlation coefficients for ampicillin and amoxycillin diluted in saline were, respectively, $r=0.993$ and $r=$ 0.995 , and after dilution in serum they were $r=0.996$ and $r=0.998$. With $S$. lutea as the test organism and with standard concentrations diluted in serum, the correlation coefficients for ampicillin and amoxycillin were, respectively, $r=0.984$ and $r=0.997$.

Blood samples were placed at $4 \mathrm{C}$ immediately after collection in order to clot, and within $2 \mathrm{~h}$ the serum was separated by centrifugation and stored at $-20 \mathrm{C}$ until the whole series was complete. The amount of urine was measured at each time, and a sample was likewise frozen at $-20 \mathrm{C}$. All assays were carried out within a few days at the end of the experiment. The determinations of the urine samples were performed on three dilutions, those of the undiluted serum samples in duplicate or triplicate. The means of the duplicate or triplicate determinations were noted, and the antibiotic concentrations were calculated from the regression lines of each drug standard. Pivampicillin levels were calculated on the ampicillin regression line, since the ester is converted in a few minutes into free ampicillin by esterases in the body.

To determine the half-life time $\left(T_{\mathrm{BO}}\right)$ for each antibiotic, the best estimate of the regression line ( $Y$ $=a \cdot e^{o X}$ ) between the time ( $X$ in minutes) from the time of the peak level to $6 \mathrm{~h}$ and the corresponding serum level ( $Y$ in micrograms per milliliter) of every volunteer was calculated by the method of the least square. $T_{\mathrm{so}}$ is given by the equation $T_{\mathrm{so}}=\ln 2 / b$, where $\ln 2$ is the natural logarithm of 2 and $b$ represents the slope of the regression line (i.e., the rate constant of the drug elimination). Most regression lines were calculated on four points, five only on three points, and four on five points.

\section{RESULTS}

Serum levels obtained after single oral administrations of $500 \mathrm{mg}$ of ampicillin or amoxy- cillin in the fasting state and $700 \mathrm{mg}$ of pivampicillin (corresponding to $500 \mathrm{mg}$ of free ampicillin) with breakfast are shown in Table 1 , together with the means and the peak levels. The mean serum levels of the three drugs are graphically presented in Fig. 1. The mean peak serum levels of pivampicillin $(11.94 \mu \mathrm{g} / \mathrm{ml})$ and of amoxycillin $(8.33 \mu \mathrm{g} / \mathrm{ml})$ were, respectively, 3.0 and 2.1 times higher than the mean peak level of ampicillin $(3.98 \mu \mathrm{g} / \mathrm{ml})$. Nine of the ten volunteers had ampicillin peak levels at $1.5 \mathrm{~h}$ and one at $2 \mathrm{~h}$. With amoxycillin the peak level occurred at $1.5 \mathrm{~h}$ in eight persons, at $1 \mathrm{~h}$ in one, and at $2 \mathrm{~h}$ in the other. With pivampicillin a larger distribution in time for reaching the peak level was observed: in four persons after $1 \mathrm{~h}$, in three after $1.5 \mathrm{~h}$, and in the remaining three after $2 \mathrm{~h}$, probably related to the fact that this drug was taken with breakfast.

The surface of the "area under the curve" was geometrically calculated for every volunteer and for each of the antibiotics, taking the time intervals in hours between the determinations as base lines and the values of the drug concentrations at every moment as the perpendiculars. Dividing this surface value by 6 (the total time in hours) resulted in an average serum level per hour over a 6 -h period for each subject. This average serum level provided the best therapeutic index for the comparison of different antibiotics with the same spectrum and in vitro activity, since it takes into account early as well as late serum levels. The values for each volunteer with the three antibiotics are shown in Table 2, together with the ratios of pivampicillin to ampicillin and amoxycillin to ampicillin. The average serum level per hour was 2.3 to 5.1 times higher with pivampicillin than with ampicillin, with a mean of 3.4 and 1.4 to 3.1 times higher with amoxycillin (mean, 2.2) compared with ampicillin. Variance analyses on the paired correlations proved that the differences between ampicillin and both other antibiotics were highly significant and that pivampicillin gave significantly higher serum levels than amoxycillin. No statistical difference in the serum values was found between males and females.

The $T_{50}$ values of all serum level curves were calculated. The correlation coefficient of the majority of regression lines was larger than 0.990 . The average $T_{s 0}$ values for the three antibiotics were nearly identical: $60.9 \mathrm{~min}$ for ampicillin (extremes, 43.1 and $99.0 \mathrm{~min}$ ); 58.4 min for pivampicillin (extremes, 43.6 and 76.2 $\mathrm{min}$ ); and $62.2 \mathrm{~min}$ for amoxycillin (extremes, 47.5 and $91.2 \mathrm{~min}$ ). A variance analysis on the paired correlations revealed no statistical difference in $T_{\text {so }}$ between the three antibiotics. 


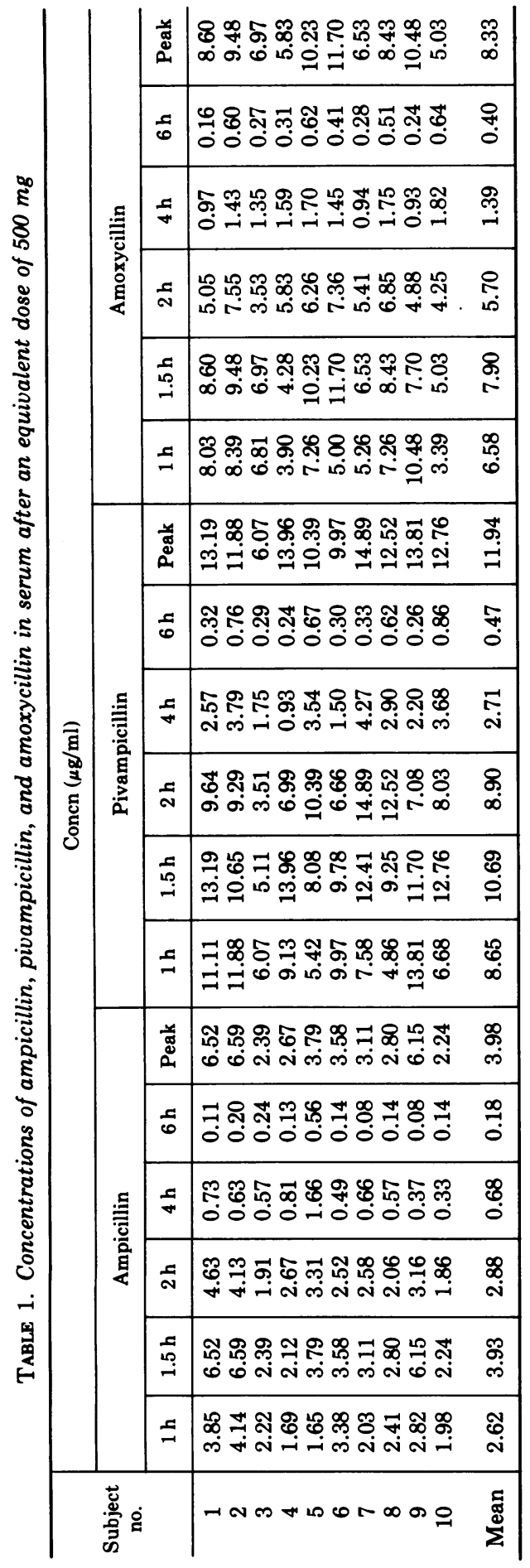

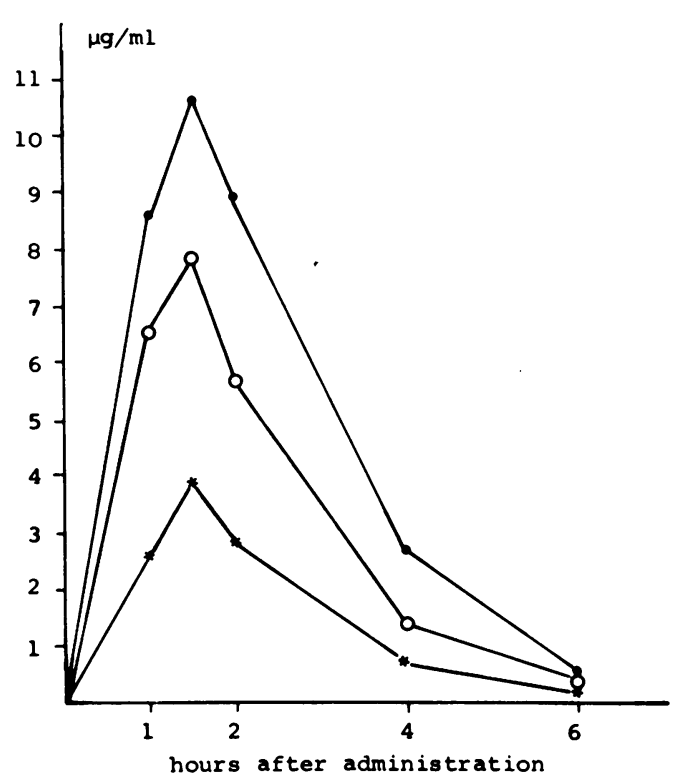

Fig. 1. Mean serum levels of ampicillin $(x)$, pivampicillin (O), and amoxycillin (O).

Urinary excretion of the drugs at different time intervals was measured. The mean cumulative quantities of active compounds recovered are graphically shown in Fig. 2. For each antibiotic, about half of the excreted dose was recovered during the first $2 \mathrm{~h}$, nearly $40 \%$ during the next $2 \mathrm{~h}$, and the remaining to a decreasing degree over the next $5 \mathrm{~h}$. On the average, $21.8 \%$ of the administered dose of ampicillin was excreted within $9 \mathrm{~h}$ against $78.5 \%$ of pivampicillin and $64.2 \%$ of amoxycillin.

Table 3 summarizes the differences in absorption between the three antibiotics as evaluated according to the following three criteria: mean peak serum levels, average serum level per hour over a 6-h period, and percentage of recovery of active compounds in urine within $9 \mathrm{~h}$. From the ratios between the drugs by all three criteria, the absorption of pivampicillin was at least three times that of ampicillin and the absorption of amoxycillin was at least twice that of ampicillin.

A good estimate of the differences in uniformity of resorption between the different drugs and within the same group of persons is given by the dispersion coefficient of the attained peak levels, calculated by the formula $V=s / \overline{\mathbf{x}}$ (standard deviation/mean) (Table 4). The dispersion coefficient was 0.44 for ampicillin, 0.22 for pivampicillin, and 0.26 for amoxycillin, indicating that the latter drugs are more uniformly absorbed than ampicillin. An $F$ test $\left(F=V_{x}{ }^{2} / V_{y}{ }^{2}\right)$ on the dispersion coefficients showed that there 
TABLE 2. Average serum level per hour over a 6-h period ${ }^{a}$

\begin{tabular}{|c|c|c|c|c|c|}
\hline \multirow{2}{*}{$\begin{array}{c}\text { Subject } \\
\text { no. }\end{array}$} & \multicolumn{3}{|c|}{ Antibiotic concn $(\mu \mathrm{g} / \mathrm{ml})$} & \multicolumn{2}{|c|}{ Ratio } \\
\hline & Ampicillin & Pivampicillin & Amoxycillin & $\begin{array}{l}\text { Pivampicillin/ } \\
\text { ampicillin }\end{array}$ & $\begin{array}{c}\text { Amoxycillin/ } \\
\text { ampicillin }\end{array}$ \\
\hline 1 & 2.25 & 5.41 & 3.12 & 2.40 & 1.39 \\
\hline 2 & 2.17 & 5.70 & 3.99 & 2.63 & 1.84 \\
\hline 3 & 1.10 & 2.55 & 2.66 & 2.32 & 2.42 \\
\hline 4 & 1.24 & 4.11 & 2.64 & 3.31 & 2.13 \\
\hline 5 & 1.86 & 4.81 & 3.73 & 2.58 & 2.00 \\
\hline 6 & 1.43 & 4.00 & 3.69 & 2.80 & 2.58 \\
\hline 7 & 1.28 & 6.56 & 2.69 & 5.12 & 2.10 \\
\hline 8 & 1.18 & 5.06 & 3.71 & 4.29 & 3.14 \\
\hline 9 & 1.66 & 4.95 & 3.32 & 2.98 & 2.00 \\
\hline 10 & .96 & 4.94 & 2.44 & 5.15 & 2.54 \\
\hline Mean & 1.51 & 4.81 & 3.20 & 3.36 & 2.21 \\
\hline
\end{tabular}

${ }^{a}$ Variance analysis on the paired correlations was: ampicillin-pivampicillin, $F_{1,0}=107.98(P<0.001)$; ampicillin-amoxycillin, $F_{1,9}=129.44(P<0.001)$; pivampicillin-amoxycillin, $F_{1,9}=20.48(P<0.01)$.

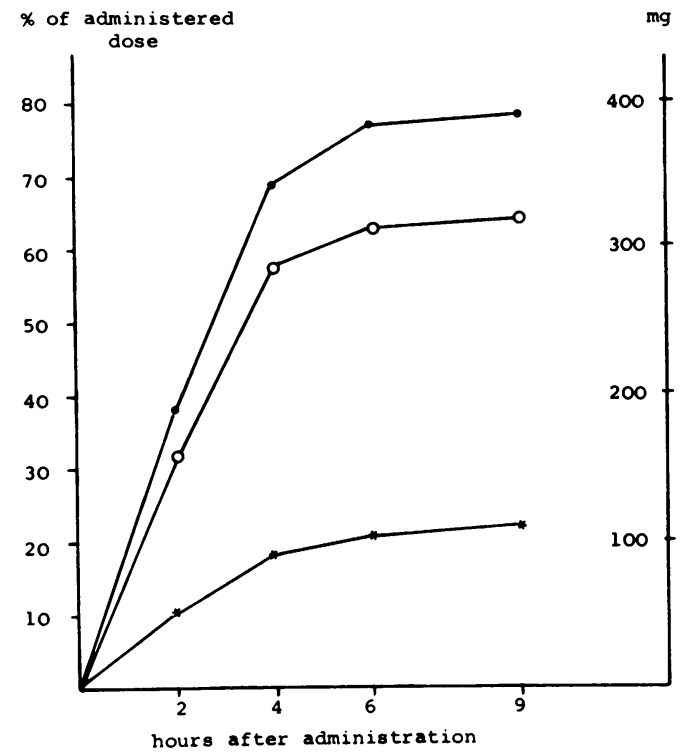

Fig. 2. Cumulative renal excretion of active compounds of ampicillin $(\times)$, pivampicillin $(O)$, and amoxycillin (O).

was a significant difference between ampicillin and pivampicillin $(P<0.025)$ but not between amoxycillin and ampicillin $(0.05<P<0.10)$ nor between pivampicillin and amoxycillin $(P$ $>0.10$ ). If the drugs are mainly excreted in urine, the same estimate on the uniformity of absorption can be made from the dispersion coefficients of urinary excretion (Table 4). These values were nearly identical: 0.46 for ampicillin; 0.22 for pivampicillin; and 0.26 for amoxycillin. Here the difference was significant between ampicillin and pivampicillin $(P<$
$0.025)$ and also between ampicillin and amoxycillin $(P=0.05)$, but not between pivampicillin and amoxycillin.

\section{DISCUSSION}

In most studies the "mean peak serum concentration" is in fact the peak value of an average serum concentration curve, whereas in this study it represents the actual mean of the individual peak values. As long as most persons reach their peak value at the same time, the difference will be small: e.g., in this study nine volunteers out of ten attained their peak value of ampicillin after $1.5 \mathrm{~h}$ and the actual mean peak value was $3.98 \mu \mathrm{g} / \mathrm{ml}$, whereas the peak of the mean serum values was $3.93 \mu \mathrm{g} / \mathrm{ml}$. However, when the individuals in a group reach their peak level at a different time after drug administration, then the peak of the mean serum concentrations of the whole group will be flattened and may differ considerably from the actual mean of the individual peak values. In this study, for instance, the peak level of pivampicillin was attained after $1 \mathrm{~h}$ by four persons, after $1.5 \mathrm{~h}$ by three, and after $2 \mathrm{~h}$ by the remaining three. As a result, the mean of the individual peak serum levels for pivampicillin was $11.94 \mu \mathrm{g} / \mathrm{ml}$, but the peak of the average serum curve of the group was only $10.69 \mu \mathrm{g} / \mathrm{ml}$ (Table 1). Considering this slight difference in methodology, the mean peak value of ampicillin in this study, $4.0 \mu \mathrm{g} / \mathrm{ml}$, corresponds very well with those obtained in other comparative studies $(6,8,9,13)$ and keeps the mean between the values reported by Bodey and Nance (1) (2.3 $\mu \mathrm{g} / \mathrm{ml})$ and by Croydon and Sutherland (2) $(6.3$ $\mu \mathrm{g} / \mathrm{ml})$. 
TABLE 3. Differences in absorption between the three antibiotics as evaluated on three criteria

\begin{tabular}{c|c|c|c|c|c|c}
\hline & & & & \multicolumn{3}{|c}{ Ratio } \\
\cline { 5 - 7 } Criterion & Ampicillin & Pivampicillin & Amoxycillin & $\begin{array}{c}\text { Pivampicillin/ } \\
\text { ampicillin }\end{array}$ & $\begin{array}{c}\text { Amoxycillin/ } \\
\text { ampicillin }\end{array}$ & $\begin{array}{c}\text { Pivampicillin/ } \\
\text { amoxycillin }\end{array}$ \\
\hline $\begin{array}{c}\text { Mean peak serum } \\
\text { level }(\mu \mathrm{g} / \mathrm{ml})\end{array}$ & $4.0(2.2-6.6)^{a}$ & $11.9(6.1-14.9)$ & $8.3(5.0-11.7)$ & 3.0 & 2.1 & 1.4 \\
$\begin{array}{c}\text { Avg serum level/h } \\
(\mu \mathrm{g} / \mathrm{ml})\end{array}$ & $1.5(1.0-2.2)$ & $4.8(2.5-5.7)$ & $3.2(2.4-4.0)$ & 3.4 & 2.2 & 1.5 \\
$\begin{array}{c}\text { Recovery (\%) in } \\
\text { urine }(0 \text { to } 9 \mathrm{~h})\end{array}$ & $21.8(7.9-41.8)$ & $78.5(41.5-99.7)$ & $64.2(40.7-93.9)$ & 3.6 & 2.9 & 1.2 \\
\hline
\end{tabular}

${ }^{a}$ Extreme values are given in parentheses.

TABLE 4. Differences in uniformity of absorption expressed by the dispersion coefficients of the peak serum levels and of the urinary excretion of the three antibiotics

\begin{tabular}{|c|c|c|c|c|c|c|}
\hline \multirow{2}{*}{ Determination } & \multicolumn{3}{|c|}{ Peak serum levels $(\mu \mathrm{g} / \mathrm{ml})$} & \multicolumn{3}{|c|}{ Urinary excretion (\% recovered) after 0 to $9 \mathrm{~h}$} \\
\hline & (A) Ampicillin & (B) Pivampicillin & (C) Amoxycillin & (A) Ampicillin & (B) Pivampicillin & (C) Amoxycillin \\
\hline $\begin{array}{l}\text { Mean } \\
\text { Standard deviation } \\
\text { Dispersion coeffi- } \\
\quad \text { cient }^{a}\end{array}$ & $\begin{array}{l}3.98 \\
1.75 \\
0.44\end{array}$ & $\begin{array}{r}11.94 \\
2.57 \\
0.22\end{array}$ & $\begin{array}{l}8.33 \\
2.19 \\
0.26\end{array}$ & $\begin{array}{l}21.8 \\
10.0 \\
0.46\end{array}$ & $\begin{array}{c}78.5 \\
17.8 \\
0.23\end{array}$ & $\begin{array}{c}64.2 \\
16.7 \\
0.26\end{array}$ \\
\hline$F$ test $^{b}$ & $\begin{array}{c}V_{\mathrm{A}}^{2} / V_{\mathrm{B}}^{2} \\
=4.175 \\
(P<0.025)\end{array}$ & $\begin{array}{c}V_{\mathrm{A}}{ }^{2} / V_{\mathrm{C}^{2}} \\
=2.797 \\
(P<0.10)\end{array}$ & $\begin{array}{c}V_{\mathrm{c}^{2}} / V_{\mathrm{B}}^{2} \\
=1.492 \\
(P>0.10)\end{array}$ & $\begin{array}{c}V_{\mathrm{A}}^{2} / V_{\mathrm{B}}^{2} \\
=4.084 \\
(P<0.025)\end{array}$ & $\begin{array}{c}V_{\mathrm{A}}{ }^{2} / V_{\mathrm{C}^{2}} \\
=3.113 \\
(P<0.05)\end{array}$ & $\begin{array}{c}V_{\mathrm{C}^{2}} / V_{\mathrm{B}}^{2} \\
=1.300 \\
(P>0.10)\end{array}$ \\
\hline
\end{tabular}

Determined as $V=$ standard deviation/mean.

- Determined as $F_{9,0}=V_{x}^{2} / V_{y}^{2}$.

The mean peak value of amoxycillin (8.3 $\mu \mathrm{g} / \mathrm{ml}$ ) agrees very well with the value of 7.6 $\mu \mathrm{g} / \mathrm{ml}$ obtained in other studies $(8,13)$ and was divergent in the same direction as ampicillin from the values obtained by Bodey and Nance (1) $(6.7 \mu \mathrm{g} / \mathrm{ml})$ and by Croydon and Sutherland (2) $(10.8 \mu \mathrm{g} / \mathrm{ml})$. Finally, the mean peak of pivampicillin found in this study $(11.9 \mu \mathrm{g} / \mathrm{ml})$ was the highest reported after a dose of $700 \mathrm{mg}$ in non-fasting healthy persons. However, when calculated, as in most studies, as the peak of the average serum levels, the peak value became $10.7 \mu \mathrm{g} / \mathrm{ml}$ and corresponds very well with the values obtained in most studies $(4,9,10)$.

The mean $T_{\mathrm{so}}$ values of $60.9 \mathrm{~min}$ for ampicillin and $62.2 \mathrm{~min}$ for amoxycillin correspond extremely well with those calculated by Gordon et al. (8) after oral administration of these drugs (60.3 and $61.3 \mathrm{~min}$, respectively). They seem to confirm that half-life time calculations from serum level curves are reliable even after oral administration and that intravenous administration of the drugs is not strictly necessary as long as at least three or more points are available for each curve and there are enough curves to obtain a reasonable sample mean. Indeed, in this study in contrast to the study of Gordon et al. (8), all curves and in these curves all values from the peak value were taken into account for the calculations, rather than only a limited group of curves selected for their straight lines on logarithmic paper. Out of the 30 calculated regression lines, 26 had a correlation coefficient of more than 0.990 and only four were lower, the lowest being 0.981 . It demonstrates that the individual serum level curves, when plotted on a semilogarithmic scale, will approximate very closely the straight line. Nevertheless, relatively large differences in half-life time may be observed between individuals within the same antibiotic group and also in the same person from one day to another, taking into account that pivampicillin will be converted in ampicillin within a few minutes after absorption. How ever, in spite of these individual and day-to-day variations, the average $T_{\mathrm{so}}$ values were nearly identical for the three antibiotics.

The recovery of amoxycillin from urine $(64.2 \%)$ was somewhat between the $59 \%$ reported by Croydon and Sutherland (2) and the $79 \%$ found by Neu and Winshell (13). That of pivampicillin $(78.5 \%)$ corresponded very well with the $77.1 \%$ recovered by Gordon et al. (8) after administration of the same dose with food. There is no explanation for the rather low percentage of ampicillin excreted in this series (21.8\% of the administered dose), since the day of administration of the different drugs was 
randomized and since the antibiotic levels were determined in blind for all three drugs on the same days. However, the difference in percentage of recovery from urine between ampicillin and both pivampicillin and amoxycillin was on the same level, although somewhat more pronounced, as were the differences in peak serum concentration or in average serum level per hour. Therefore, the low recovery in urine indicates poor absorption of ampicillin.

With regard to the three criteria that may reflect the absorption of the drugs in this triple crossover experiment (mean peak serum levels, average serum levels per hour over a 6 -h period, and percentage of recovery in urine) and taking into account that the $T_{50}$ values were nearly identical, pivampicillin was the best-absorbed drug, followed by amoxycillin. By these criteria, pivampicillin displayed a 3.00 - to 3.6 -fold higher absorption than ampicillin and a 1.2- to 1.5 -fold higher absorption than amoxycillin, whereas the absorption of amoxycillin was 2.1 to 2.9 times higher than that of ampicillin. Furthermore, pivampicillin and amoxycillin were more uniformly absorbed than ampicillin by the different individuals within a group, as demonstrated by the lower dispersion coefficients of the peak serum levels and of the urinary excretion. This is extremely important for the reliability of any chemotherapy.

Therefore, it may be concluded that both pivampicillin and ampicillin are superior substitutes for oral ampicillin therapy and that they can compete very well with parenteral therapy with ampicillin. Clinically, pivampicillin, which is best taken together with food, may be the better choice, since drug administration on an empty stomach is not always feasible and in practice is very often neglected by the patient.

\section{ACKNOWLEDGMENTS}

This investigation was supported by grants from Leo Pharmaceuticals and from Bristol Laboratories.

\section{LITERATURE CITED}

1. Bodey, G. P., and J. Nance. 1972. Amoxicillin: in vitro and pharmacological studies. Antimicrob. Ag. Chemother. 1:358-362.

2. Croydon, E. A. P., and R. Sutherland. 1971. $\alpha$-Amino-phydroxybenzylpenicillin (BRL 2333), a new semisynthetic penicillin: absorption and excretion in man, $p$. 427-430. Antimicrob. Ag. Chemother. 1970.

3. Daehne, W. von, E. Frederiksen, E. Gundersen, F. Lund, P. Morch, H. J. Petersen, K. Roholt, L. Tybring, and W. O. Godtfredsen. 1970. Acyloxymethyl esters of ampicillin. J. Med. Chem. 13:607-612.

4. Daehne, W. von, W. O. Godtfredsen, K. Roholt, and L. Tybring. 1971. Pivampicillin, a new orally active ampicillin ester, p. 431-437. Antimicrob. Ag. Chemother. 1970.

5. Fernandez, C. A., J. P. Menezes, and J. Ximenes. 1973. The effect of food on the absorption of pivampicillin and a comparison with the absorption of ampicillin potassium. J. Int. Med. Res. 1:530-533.

6. Foltz, E. L., J. W. West, I. H. Breslow, and H. Wallick. 1971. Clinical pharmacology of pivampicillin, p. 442-454. Antimicrob. Ag. Chemother. 1970.

7. Frederiksen, E., W. O. Godtfredsen, B. Nielsen, and K. Roholt. 1971. Pivampicillinklorid et nyt bredspektret antibiotikum til oral anvendelse. Nord. Med. 86:1376-1380.

8. Gordon, R. C., C. Regamey, and W. M. M. Kirby. 1972 Comparative clinical pharmacology of amoxicillin and ampicillin administered orally. Antimicrob. Ag. Chemother. 1:504-507.

9. Hultberg, E. R., and B. Backelin. 1972. Studies on the absorption of pivampicillin and ampicillin. Scand. J. Infect. Dis. 4:149-153.

10. Jordan, M. C., J. B. de Maine, and W. M. M. Kirby 1971. Clinical pharmacology of pivampicillin as com. pared with ampicillin, p. 438-444. Antimicrob. Ag. Chemother. 1970.

11. Magni, L., and J. Sjövall. 1972. Absorption of ampicillin and pivampicillin in relation to food intake. Farm. Tidinde 32:645-648.

12. Neu, H. C., and E. B. Winshell. 1971. In vitro antimicrobial activity of $6[\mathrm{D}(-) \alpha$-amino- $p$-hydroxyphenylacetamido] penicillanic acid, a new semisynthetic penicillin, p. 407-410. Antimicrob. Ag. Chemother. 1970.

13. Neu, H. C., and E. B. Winshell. 1971. Pharmacological studies of $6[\mathrm{D}(-) \alpha$-amino-p-hydroxyphenylacetamido] penicillanic acid in humans, p. 423-426. Antimicrob. Ag. Chemother. 1970.

14. Sutherland, R., and G. N. Robinson. 1971. $\alpha$-Amino-phydroxybenzylpenicillin (BRL-2333), a new semisynthetic penicillin: in vitro evaluation, p. 411-415. Antimicrob. Ag. Chemother. 1970. 